\title{
Antibacterial Activity of Clerodendron Infortunatum and Scoparia Dulcis - A Comparative Study
}

\author{
C.K. Mohandas ${ }^{1}$, P.K. Valsalakumari ${ }^{1}$, Hellen William ${ }^{1}$ and Dr. N. Narayanan ${ }^{2}$ \\ ${ }^{1}$ Research Scholars, Periyar Maniamman University, Thanjavoor, Tamil Nadu \\ ${ }^{2}$ Professor and Director of Research Jaya College of Pharmacy, Chennai
}

\begin{abstract}
Invitro antibacterial activity of ethnolic extract of leaves of Clerodendron infortunatum and whole herb of Scoporia dulcis were compared in the present study by agar-well diffusion method using two human pathogenic bacterial strains. The activity was measured by determining zone of exhibition. The zone of inhibition values were compared with the standard Gentamycin $(20 \mathrm{mg} / \mathrm{ml})$. Streptococcus mutans and Pseudomonas aeroginosa are the organisums used. The study conclude that etholics extract of Scoparia dulcis exhibited more antibacterial activity than ethnolic exctrat of Clerodendron infortunatum.
\end{abstract}

Keywords: Clerodendron infortunatum, Scoparia dulcis , Agar-well diffusion, Antibacterial activity.

\section{Introduction:}

Medicinal plants are natural resouorces yeilding valuable herbal products which are often used in the treatment of various ailments.For this purpose the use of plant extracts in traditional medicine has been going on from ancient time.Herbalism and folk medicine, both ancient and modern, have been the source of much useful therapy.During the last twenty years renewed interest has emerged to help developing safer antimicrobial drugs from the natural sources, presumably due to the increasing development of drug resistance to human pathogenic organisms, as well as the appearance of undesirable side effects of certain antibiotics and the emergence of previously uncommon infections.

C. infortunatum is a flowering shrub and is so named because of its rather ugly leaf. The stem is eresct, 0.5-4 high, with no branches and produce circular leaves with 6 inch diameter. Leaves are simple, opposite; both surfaces sparsely villours-pubes-centm elliptic, broadly elliptics, ovate or elongat ovate, $3.5-20 \mathrm{~cm}$ wide, 6$25 \mathrm{~cm}$ long, dentate, inflorescence in terminal, peduncled, few-flowered cyme; flowers white with purplish plink or dull purple throat, pubescent. Fruit berry, globose, turned bluish-black or black when ripe, enclosed in the red accrescent fruiting-calyx. The stem is hollow and the leaves are 6-8 inch $(15-20 \mathrm{~cm})$ long, bornes in whorls of fouor on very short petioles. The inflorescence is huge consisting of many tubular snow white flowers in a terminal cluster up to $2 \mathrm{ft}(0.6 \mathrm{~m})$ long. The tubes of the flowers are about 4 inch $(10 \mathrm{~cm})$ long and droop downward, and the expanded corollas are about 2 inch $(5 \mathrm{~cm})$ across. The fruits are attractive dark metallic blue drupes, about a half inch in diameter, Fruit usually with 4 dry nutlets and the seeds may be with or without endosperm. It flowers from April to August [1]

The major constituents are sterols, sugars, flavonoids and saponins. Novel crystalline compounds such as clerodolone, clerodone, clerodol and a sterol designated clerosterol have been isolated from the root. Seven sugars namely raffinose, lactose, maltose, sucrose, galactose, glucose and fructose were identified [2]. Fumaric acid, caffeic acid esters, B-stiosterol and B-sitosterol glucoside were isolated from the flowers. [3] Apigenin, acacetin and a new flavone glycoside, characterised as the methyl ester of acacetin 7-0-glucuronide are islated from the flowers.[4] Saponin is one of the major compounds of the leaf.[5] 24 beta-ethylsterols, clerosterol and 22-dhydroclerosterol, 24-methyl-sterols (24-methylcholestanol, 24-methylcholesterol, 24-methyl-22dehydrochlesterol, and 24-methyllathostero) and 24 beta-ethyl-229dehydrochlestanol are found in the seeds.[6] Scutellarin and hispidulin-7-0glucuronide are present in the leaf.[7] Poriferasterol and stigmasterol are the components of the aerial parts.[8]

In Ayurvedic and Siddha traditional medicines, the leaves and roots of C. Infortunatum are used as herbal remedy for alopecia, asthma, cough, diarrhoea, rheumatism, fever and skin diseases. It is also known to have hepato-protective and antimicrobial activities.

Scoparia dulcis L, commonly known as sweet broom weed is a perennial herb widely distributed in tropical and subtropical regions.In these regions, fresh or dried S. dulcis plants have been traditionally used as remedies for stomach troubles, hypertension (9), diabetes, bronchitis(10) and as analgesic and antipyretic agents(11). In view of its high reputation and wide acceptance in ethnomedicine this plant has attracted not only wide publicity but also intensified research efforts by researchers(12). More recently, a number of the speculated medicals values of $\mathrm{S}$. dulcis have been validated by sacientific research. These include hypoglycemic activity (13), antitumour promoting activity (14), antiviral activity(15), hyperlipidemic activity(16), antioxidant and analgesic activity(17). A significant analgesic activity was also demonstrated along 
with the antithyperalgesic activity for S. dulcis decoction(18). Later it was investigated the antibacterial and antifungal activity of S. dulcis(19) by another author. Pure diterpense extracted from S. dulcis was reported to show cytotoxicity towards six human stomach cancer cell lines.Phytochemical screening of the herb reveled that it is rich in flavonoids and terpenes and the pharmacological actions of $\mathrm{S}$. dulcis are believed to be due to the presence of these phytochemicals. The main chemicals include scopadulcic acids A and B, scopadio, scopadulciol, scopadulin, scoparic acids A-C and betulinic acid.S.dulcis also contains coumarins, phenols,saponins, tannins, aminoacids, alkaloids, carbohydrates, glycosides. Some of these compounds are seems to be active against certain bacteria. This may leads to the traditional use as medicinal plants.

Plant Material:-

\section{Materials and Methods:}

a) The plant C.infortunatum Linn. was collected from the capmus of Government Medical College, Kottayam District of Kerala in February 2014 and indentified at Jawaharlal Nehru Tropical Botanical Garden and Research Institute (JNTBGRI), Palode, Thiruvananthapuram, Kerala as specimen No: TBGT No. 30757.

b) The plant S. dulcis was collected from Nagarcoil District of Tamil Nadu in August 2013 and identified at JNTBGRI Palode, Thiruvananthapuram, Kerala as specimen No. TBGT No.26594

\section{Preparation of Extrac :-}

a) The leaves of $\mathrm{C}$. Infortunatum was dried under shade and made in to coarse powder. Then the powdered plant material was extracted with $95 \%$ ethanol by maceration method. The extract was collected and solvent completely removed by distillation under reduced pressure. A semisolid to solid mass was obtained.

b) The whole plant of S. dulcis was dried under shade and made in to course powder. Then the powdered material was extracted with $95 \%$ ethanol by maceration method and the solvent was completely removed by spray dried method.

\section{Antimicrobial activity}

Agar-well diffusion method

Principle

The antimicrobial constituents present in the plant extract are allowed to diffuse out into the medium and interact in a plate freshly seeded with the test organisms. The resulting zones of inhibition will be uniformly circular as there will be a confluent lawn of growth. The diameter of zone of inhibition can be measured in millimetre.

\section{Reagents}

\section{Muller Hinton Agar Medium (1L)}

The medium was prepared by dissolving $33.9 \mathrm{~g}$ of the commercially available Muller Hinton Agar Medium (HiMedia) in $1000 \mathrm{ml}$ of distilled water. The dissolved medium was autoclaved at $15 \mathrm{lbs}$ pressure at $121^{\circ} \mathrm{C}$ for 15 minutes. The autoclaved medium was mixed well and poured on to $100 \mathrm{~mm}$ petriplates $(25-$ $30 \mathrm{ml} /$ plate) while still molten.

\section{Nutrient broth (1L)}

One litre of nutrient broth was prepared by dissolving $13 \mathrm{~g}$ of commercially available nutrient medium (HiMedia) in $1000 \mathrm{ml}$ distilled water and boiled to dissolve the medium completely. The medium was dispensed as desired and sterilized by autoclaving at 15 pressure $\left(121^{\circ} \mathrm{C}\right)$ for 15 minutes.

\section{Gentamycin (standard antibacterial agent, concentration : $20 \mathrm{mg} / \mathrm{ml}$ ) Procedure}

Petriplates containing $20 \mathrm{ml}$ Muller Hinton Medium were seeded with $24 \mathrm{hr}$ culture of bacterial strains of Streptococcus mutans and Pseudomonas aeroginosa. Wells of approximaately $10 \mathrm{~mm}$ was bored using a well cutter and $25 \mathrm{pl}, 50 \mathrm{pl}$ and $100 \mathrm{pl}$ of samples were added to the well. The plates were then incubated at $37^{\circ} \mathrm{C}$ for 24 hours. The antibacterial activity was assayed by measuring the diameter of the inhibition zone formed around the well (NCCLS, 1993). Gentamycin was used as a positive control.

Reference: National Committee for Clinical Laboratory Standards. (1993a). Performance Standards for Antimicrobial Disk Susceptibility Tests-Fifth Edition: Approved Standard M2-A5. NCCLS, Villanova, PA 
III. Result
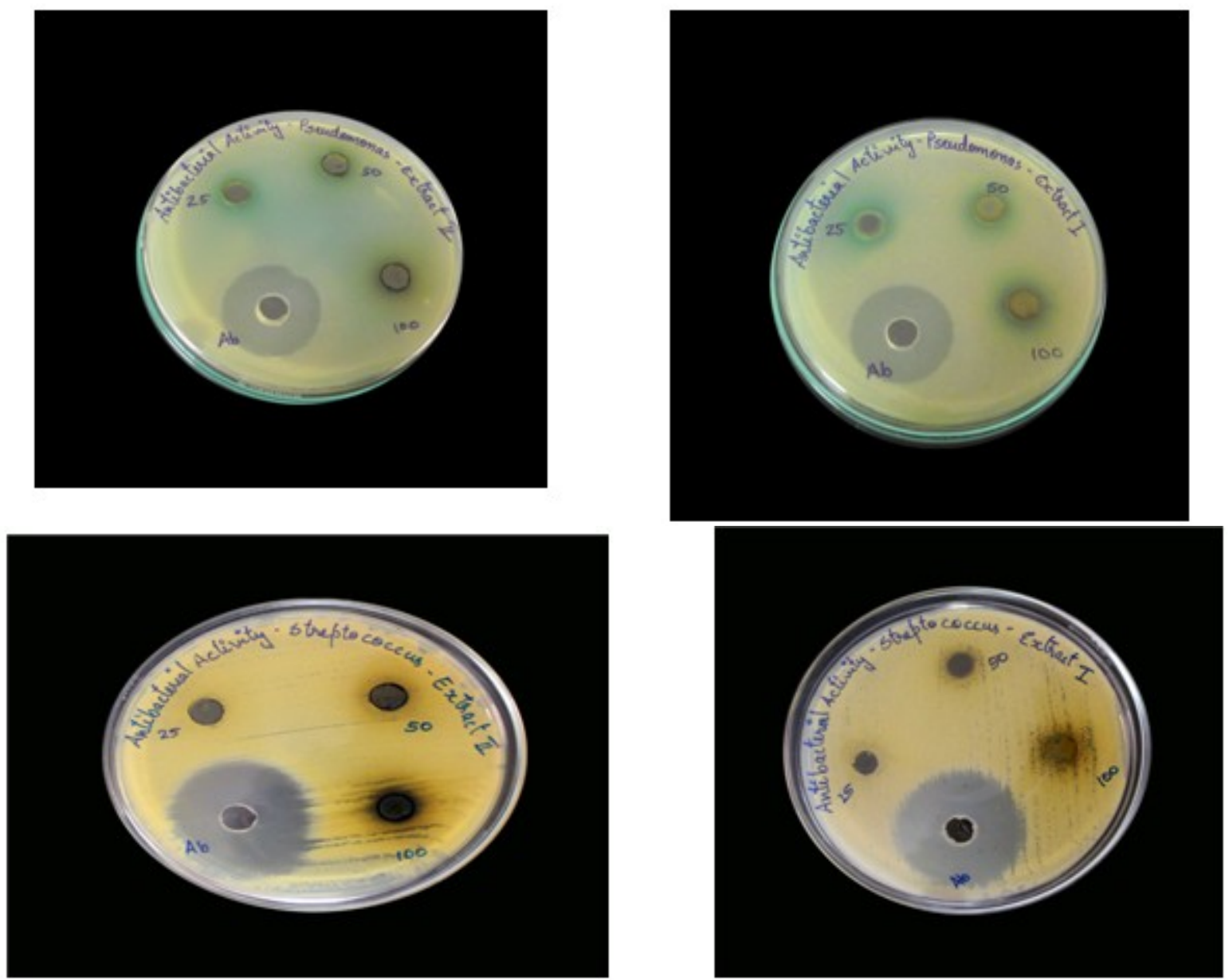

\begin{tabular}{|l|l|l|}
\hline Extract & Product & Organisms \\
\hline I & C.infortunatum & $\begin{array}{l}\text { S. mutans and } \\
\text { P. aeruginosa }\end{array}$ \\
\hline II & S. dulcis & $\begin{array}{l}\text { S. mutans and } \\
\text { P. aeruginosa }\end{array}$ \\
\hline
\end{tabular}

Organism: Streptococcus mutans

\begin{tabular}{|l|l|l|}
\hline Sample & Volume of Sample $(\mu \mathrm{l})$ & Zone of inhibition $(\mathrm{mm})$ \\
\hline Gentamycin & & 33 \\
\hline EXTRACT 1 & & \\
\hline (C. infortunatum) & 25 & Nil \\
\hline & 50 & Nil \\
\hline & 100 & Nil \\
\hline EXTRACT 2 & & \\
\hline (S. dulcis) & 25 & Nil \\
\hline & 50 & Nil \\
\hline & 100 & 11 \\
\hline
\end{tabular}

Organism: Pseudomonas aeroginosa

\begin{tabular}{|l|l|l|}
\hline Sample & Volume of Sample $(\mu \mathrm{l})$ & Zone of inhibition $(\mathrm{mm})$ \\
\hline Gentamycin & & 30 \\
\hline EXTRACT 1 & & \\
\hline (C.infortunatum) & 25 & Nil \\
\hline
\end{tabular}




\begin{tabular}{|l|l|l|} 
& 50 & Nil \\
\hline EXTRACT 2 & 100 & 9 \\
\hline (S.dulcis) & & \\
\hline & 25 & Nil \\
\hline & 50 & Nil \\
\hline & 100 & 10 \\
\hline
\end{tabular}

NOTE: sample concentration : 100mg/1ml

\section{Discussion:}

The present study revealed that the ethnolic extract of both medical plants Clerodedron infortunatum and Scoparia dulcis has antibacterial activity, Antibacterial activity of the compounds may be of four types:1) they hamper cell wall synthecis (2) they inhibit microbial protein and nucleic acid synthesis.(3) they disrupt microbial membrane structure and function, and (4) they block metabolic path way through inhibition of key enzymes. In the present study the ethnolic exract of Clerodundron infortunatum showed average zone of inhibition of $9 \mathrm{~mm}$ with P.aeroginosa and nil zone of inhibition with S. Mutans.Ethnolic extract of Scoparia dulcis showed zone of inhibition of $10 \mathrm{~mm}$ with P. aeroginosa and $11 \mathrm{~mm}$ with S. mutans. Antibacterial activity against both gram positive (S. mutans) and gram negative (P. aeroginosa) bacteria may be indicative of the presence of broad spectrum antibiotic compound.

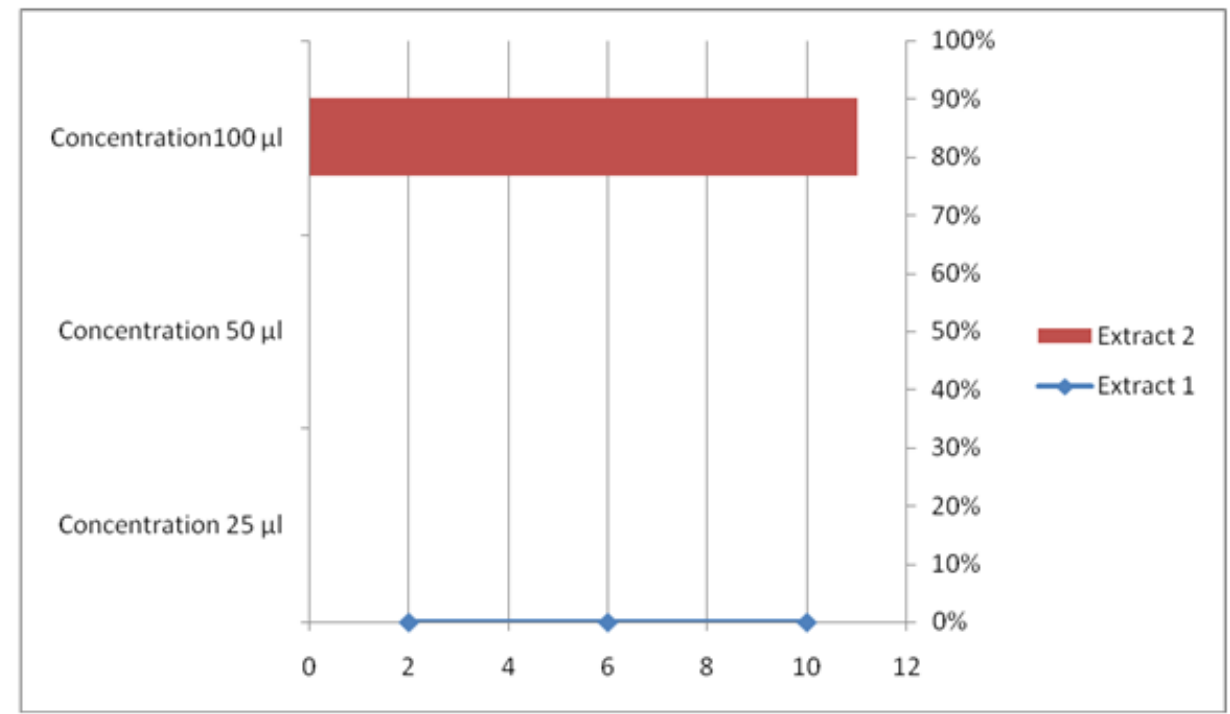

Organism used:- S. mutans

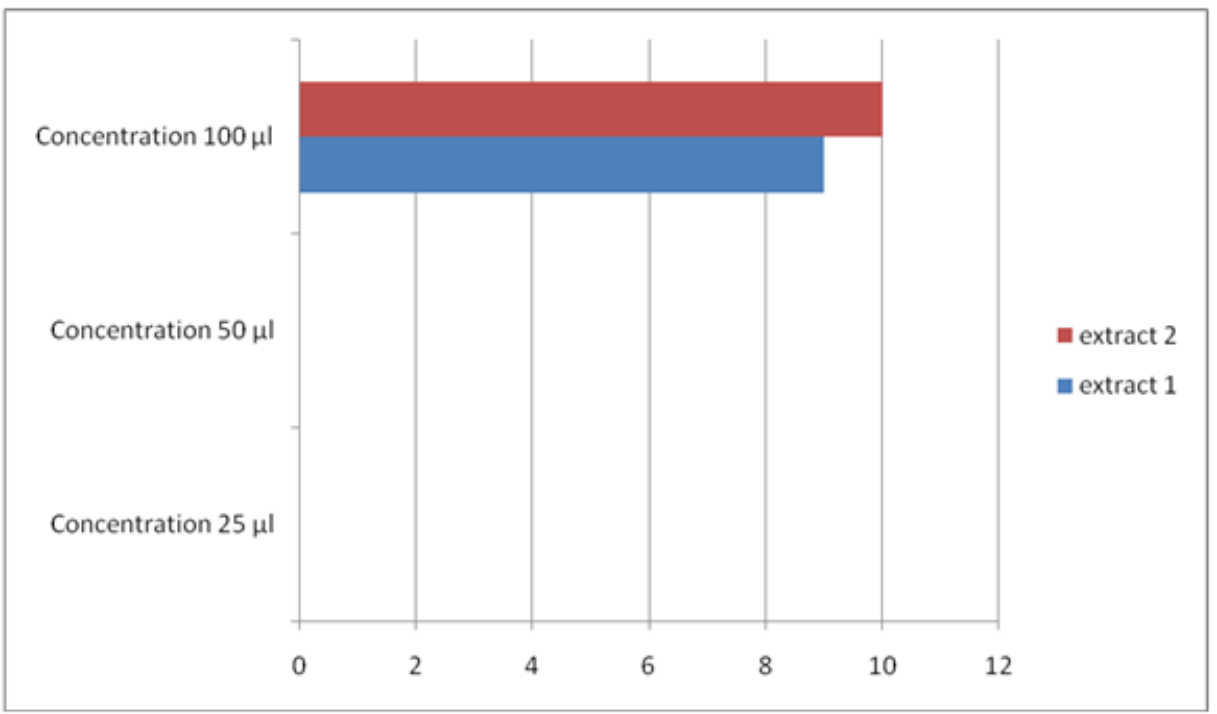

Organism used:- P. aeroginosa 


\section{Conclusion:}

Based on the results it can be concluded that the ethnolic extract of Scoparia dulcis has potential antibacterial activity against both gram positive and gram negative organisums than the ethnolics entract of Clarodendron infortounatum. Hence crude extract of Scoparia dulcis may be utilized in the treatment of infectious diseases caused by the resistant organisums. The present study offers a scientific basis for traditional use of crude drugs. Further evaluation of the antibacterial properties of the plant extract against a more extensive panel of microbial agents is reasonable.

\section{Reference:}

[1]. Jayaweera DMA (982), Medicinal Plants (Indigenous and Exotic) Used in Ceylon Part V. The National Science Council of Sri Lanka, Colombo, pp- 160-161

[2]. Manzoor-Khuda M, Sarela S (1965). "Constituents of Clerodendron infortunatum (bhat)- I : Isolation of clerodolone, clerodone, clerodol and clerosterol" Tetrahedron 21 (4): 797-802. doi:10,1016/0040-4020(65)80012-6.

[3]. Sinha NK, Pandey VB, Shah AH, Dasgupta B (1980), "Chemical constituents of the flowers of Clerodendron [Clerodendrum] infortunatum". Indian Journal of Pharmaceutical Sciences 42 (3):96-97

[4]. Sinha NK, Seth KK, Pandey VB, Dasgupta B, Shah AH (1981), "Flavonoids from the flowers of Clerodendron infortunatum". Planta Med 42 (7):296-298. doi:10.1055/s-2007-971645. PMID 17401979.

[5]. Pal D, Sannigrahi S, Mazunder UK (2009) "Analgesi and anticonvulsant effects of saponin solated from the leaves of Clerodendrum infortunatum Linn. In mice”. Indian J Exp Biol 47 (9): 743-747. PMID 19957887.

[6]. Akihisa T, Matsubara Y, Ghosh P, Thakur S, Tamura T, Matsumoto T. (1989). "Sterols of some Clerodendrum species (Verbenaceae): occurrence of the 24 alpha-and 24 beta-epimers of 24-ethylsterols lacking a delta 25-bon". Steroids 53 (3-5): 625638. PMID 2799860.

[7]. Subramanian SS, Nair AGR (1973). "Scutellarin and hispidulin-7-0-glucuronide from the leaves of Clerodendrum indicum and Clerodendron infortunatum".

[8]. Akihisa T, Matsubara Y, Ghosh P, Thakur S, Tamura T, Matsumoto T. (1989). "Sterols of some Clerodendrum species (Verbenaceae): occurrence of the 24 alpha-and 24 beta of 24-ethylsterols lacking a delta 25-bond". Steroids 53 (3-5): 625-638. PMID 2799860.

[9]. Jain HC. Indian plants with Oral Hypoglycaemic activity. Abstr, Internat. Res. Cong. Nat. Prod.Coll. Pharm. Univ. N. Carolina Chapel Hill, NC 1985; July 7-12, Abstr.: p, 152.

[10]. Latha M, Pari L, Sitasawad S and Bhonde R. Scoparia dulcis, a traditional antidiabetic plant, protects against streptozotocin-induced oxidative stress and apoptosis in vitro and in vivo. J. Biochem. Toxicol, 2004a; 18(5):261-272.

[11]. Latha M, Pari L, Sitasawad S and Bhonde R (2004). Insulin secretagogue activity and cytoprotective role of the traditional antidiabetic plant Scoparia dulcis. Life Sci. 2004B; 75(16): 2003-2014.

[12]. Pari L and Venketaswaran. Hypoglycaemic activity of Scoparia dulcis L, extract in alloxan-induced hyperglycaemic rats. Phytotherapy Research 2002; 16(7):662-664

[13]. Pari L and Latha M. Antihypoglycaemic activity of Scoparia dulcis: effect on key metabolic enzymes of carbohydrate metabolism in streptozotocin-induced diabetes. Pharma. Biol. 2005;42(8):570-576

[14]. Nishino H., et al. Antitumor-promoting activity of scopadulcic acid B, isolated from the medicinal plant Scoparia dulcis L., Oncology 1993; 50(2): 100-3

[15]. Hayashi T, Kawasaki M, Miwa Y, Taga T and Morita N. Antiviral agents of plant origin. III. Scopadulin, a novel tetracyclic diterpene from Scoparia dulcis L, Chemical Pharmaceutical Bulletin 1990; 38: 945-947.

[16]. Orhue NEJ and Nwanze EAC. Scoparia dulcis reduces the severity of Trypanosoma bruceiinduced hyperlipidaemia in the rabbit. African Journal of Biotechnology 2006; 5(10): pp, 883-887.

[17]. AHM Zulfiker, M Mahbubur Rahman, M Kamal Hossain, K Hamid, MEH Mazunder and M Sohel Rana. In vivo analgesic activity of ethanolic extracts of two medicinal plants-Scoparia dulcis L. and Ficus racemosa Linn. Biology and Medicine 2010;2(2):42-48.

[18]. Ratnasooriya WD, Galhenag, Liyanage SSP, Jayakody JRAC and Ediriweera ERHSS.Analgesic and antihyperalgesic effects of Scoparia dulcis decoction in rats. J. Trp. Med. Plants 2003; 4 (1): 63-69

[19]. M Latha, KM Ramkumar, L Pari, PN Damodaran, V Rajeshkannan and T Suresh, Phytochemical and antimicrobial study of an antidiabetic plant : Scoparia Dulcis L. J Med Food 2006; 9(3):391-39. 